\title{
CIRCULATORY CHANGES IN MITRAL STENOSIS AT REST AND ON EXERCISE
}

\author{
BY \\ J. D. BALL, H. KOPELMAN, AND A. C. WITHAM* \\ From the Department of Medicine, Postgraduate Medical School of London \\ Received December 31, 1951
}

There is some increase in the pulmonary artery pressure in many patients with mitral stenosis and this pressure may rise considerably on exercise as was first shown by Hickam and Cargill (1948). Gorlin and Gorlin (1951) have described a method of calculating the area of the mitral orifice in life and Gorlin et al. (1951 $a$ and $b$ ) have attempted to evaluate the factors causing this pulmonary hypertension at rest and on exercise. Although in these cases, the stenosed mitral valve must be the primary cause, other changes that may occur in the pulmonary vasculature or in the pulmonary blood volume may also be of importance. Lagerlöf et al. (1949) and Borden et al. (1949) using the Hamilton method, injecting dye directly into the pulmonary artery, showed no increase in the pulmonary blood volume in patients with mitral stenosis at rest. Kopelman and Lee (1951) verified these findings with dye injected into an antecubital vein and also showed no significant increase in the intrathoracic blood volume in mitral stenosis even when in congestive cardiac failure. This was in contrast with patients in left ventricular failure who showed a well marked increase in intrathoracic blood volume.

The Hamilton dye method has been used in a further study of patients with mitral stenosis to determine the changes in cardiac output and intrathoracic blood volume that occur during mild exercise.

\section{MATERIAL AND MethodS}

Sixteen patients with mitral stenosis were investigated. Some of these had auscultatory signs of aortic valve involvement but mitral stenosis was considered to be the predominant lesion. None had clinical signs of congestive cardiac failure at the time of the investigation. Previous experience has shown that the presence of a giant left atrium or of tricuspid regurgitation prevents a reliable result with the method used, and no patient investigated had either of these conditions. Nine subjects without evidence of cardiovascular disease were similarly investigated.

The Hamilton dye method consists of the injection of a known amount of dye (Evans Blue T 1824) into an antecubital vein and the collection of rapidly timed arterial samples. From these a time-concentration curve can be constructed and the cardiac output and mean circulation time calculated as described by Hamilton et al. (1932). By the application of Stewart's formula (1921) the volume of blood between injection and sampling points can be determined and this has been referred to as the "intrathoracic blood volume."

In a series of five duplicate tests at rest, the coefficient of variation for the intrathoracic blood volume was found to be 6.5 per cent: although the number is small, changes in the intrathoracic blood volume of more than 13 per cent are probably significant. Similarly changes in the cardiac output of the same order are probably significant, the summation of errors in the technique being 6 per cent (Hamilton et al., 1948; Kopelman and Lee, 1951). It has been found that the cardiac output obtained by this method corresponds

* Fellow of the U.S. Public Health Service. 
closely with that obtained by the direct Fick principle (Hamilton et al., 1948; Lagerlöf et al., 1949; Kopelman and Lee, 1951).

Patients were investigated in their beds, comfortably seated at an angle of 30 to 40 degrees. They were fasted but not sedated and the procedure was made painless by careful local infiltration over both puncture sites. The test was done first at rest, as described by Kopelman and Lee (1951), and then repeated fifteen minutes later during leg exercises. These were performed by alternately compressing and releasing two foot pumps arranged on a support which could be fitted to the end of the bed. The duration of exercise was approximately five minutes, but was less in the more severe cases of mitral stenosis as it was discontinued as soon as there was much dyspnœa. No real attempt was made to standardize the exercise because of this variation in functional capacity. The indwelling arterial needle was left in situ for both tests and it was found that with a closely fitting stilette, which extended 1 or $2 \mathrm{~mm}$. beyond the needle tip, adequate samples could be obtained for the second study in most cases.

All patients had teleradiograms taken at rest and immediately after exercise. From these the cardiothoracic $(C / T)$ ratio was determined by the method described by Meneely and Chesnut (1947). The pulmonary artery was noted as being normal, enlarged, or very enlarged, but no measurement was attempted. In some of these patients cardiac catheterization was performed and intracardiac pressure recorded, but these were not performed on the same day as the dye test.

\section{Results in Normal CONTROLS}

The results in patients with normal cardiovascular systems are shown in Táble $\mathrm{I}$. The mean resting cardiac index was 3.3 litres which increased on exercise to 4.3 litres per square metre of body surface. Most cases showed a significant increase in the cardiac index on exercise, but this was variable in extent, probably because of differences in training and fitness, as has been found by Riley et al. (1948) and Dexter et al. (1951) using the catheter technique.

The intrathoracic blood volume index at rest was 1.22 litres and increased on exercise to 1.43 litres per square metre of body surface. Four of the nine subjects, however, showed no significant rise in intrathoracic blood volume, although in three of these (C43, C27, and C37) there was a marked rise in cardiac output. The mean circulation time in these patients decreased more than in the others. This suggests that in mild exercise in normal subjects, the increase in blood flow can cause either an increase in the intrathoracic blood volume or a speeding up of the circulation in the thorax or both.

\section{Results in Mitral Stenosis}

Table II shows the results obtained in patients with mitral stenosis arranged in descending order of their cardiac indices. Stead et al. (1945) found that the average cardiac index at rest in a group of normal subjects was 3.3 with a range of $2 \cdot 3$ to $4 \cdot 1$ litres per square metre of body surface. In the present series the lower limit for the normal resting cardiac index has been taken as 2.5 litres and the patients with mitral stenosis subdivided into two groups: $(a)$ those with a normal cardiac index at rest, that is greater than 2.5 litres, and $(b)$ those with a low resting cardiac index, that is less than $2 \cdot 5$ litres per square metre.

(a) Normal Resting Cardiac Index. Nine patients were found to be in this group with a mean cardiac index of 3.4 litres. Four of these were able to increase their cardiac index on mild exercise to more than 4.3 litres, i.e. a slightly greater cardiac output response than the average normal. All four showed some increase in intrathoracic blood volume, with the mean circulation time remaining the same or decreasing slightly. In the other five patients in this group who had a slightly lower cardiac index at rest, the increase in cardiac index on exercise was less and in no case did it reach 4.0 litres per square metre; in two there was no significant rise. All but one of these showed a prolongation of the mean circulation time on exercise with a corresponding increase in the intrathoracic blood volume. This prolongation in mean circulation time was not found so consistently in any other group. 


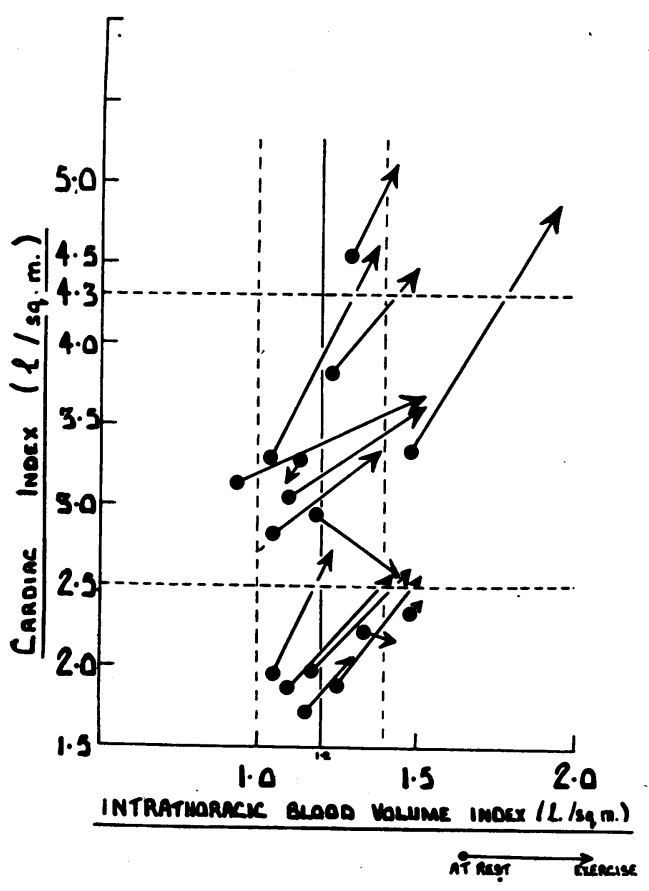

FIG. 1.-Changes in the cardiac index and intrathoracic blood volume index in exercise in mitral stenosis. The mean value for the intrathoracic volume index in 9 normal subjects is shown at $1 \cdot 2$ litres with the vertical broken lines indicating the standard deviation of these observations. been arranged in the same order as before. It is apparent that the cases with low cardiac outputs

(b) Low Resting Cardiac Index. There were seven patients in this group with a mean cardiac index at rest of 2.0 litres, although five actually had cardiac indices less than this. All except two of these patients showed some rise in the cardiac index on exercise, the mean being 2.4 litres: none were able to reach 3.0 litres per square metre. The intrathoracic blood volume rose in all cases on exercise except in the two showing no change in cardiac output. This was accompanied by a small decrease in the mean circulation time. The mean increase was less than in the previous group but the difference was not statistically significant $(t=1 \cdot 56 ; p>0 \cdot 1)$.

The changes in cardiac output and intrathoracic blood volume that occur on exercise are diagrammatically shown in Fig. 1 . From the results in the present series and from those of Kopelman and Lee (1951) there appears to be a close relationship between the resting cardiac output and the mean circulation time in normals and in mitral stenosis whether in congestive failure or not. This is demonstrated in Fig. 2. Thus the mean circulation time is within the normal range in the patients with mitral stenosis with normal resting cardiac indices but becomes greatly prolonged in those with low resting values.

\section{Clinical Features}

In Table III some of the clinical and radiological data have been listed; the patients having at rest have the larger hearts as indicated by the increase in the cardio-thoracic ratio. This inverse relationship between cardiac output and heart size in mitral stenosis is well shown in Fig. 3 which is obtained from the present data and those of Kopelman and Lee (1951). This relationship does not hold for patients with left ventricular failure $(r=-0 \cdot 16 ; p>0 \cdot 1)$. On exercise no measurable increase in the cardio-thoracic ratio in any patient occurred although in a few cases the main pulmonary artery appeared a little more prominent.

A previous history of congestive cardiac failure was present in all patients showing low resting cardiac outputs. Some with normal cardiac outputs also gave histories of mild congestive failure but only those with poor exercise responses. In these patients auricular fibrillation was nearly always present.

Patients have also been classified into the grades of functional capacity defined by the New York Heart Association (1939). Many, however, had functional capacities that varied from time to time under varying circumstances and it was found convenient to indicate this by placing them between the two relevant grades. It can be seen that the functional capacity appeared to decrease as the resting cardiac index fell.

\section{Discussion}

Wide differences in cardiac output and mean circulation time were present in the normal group and in those patients with mitral stenosis who still had normal resting cardiac outputs (Tables I and II). This could be explained by mild apprehension felt by some patients during the test so 


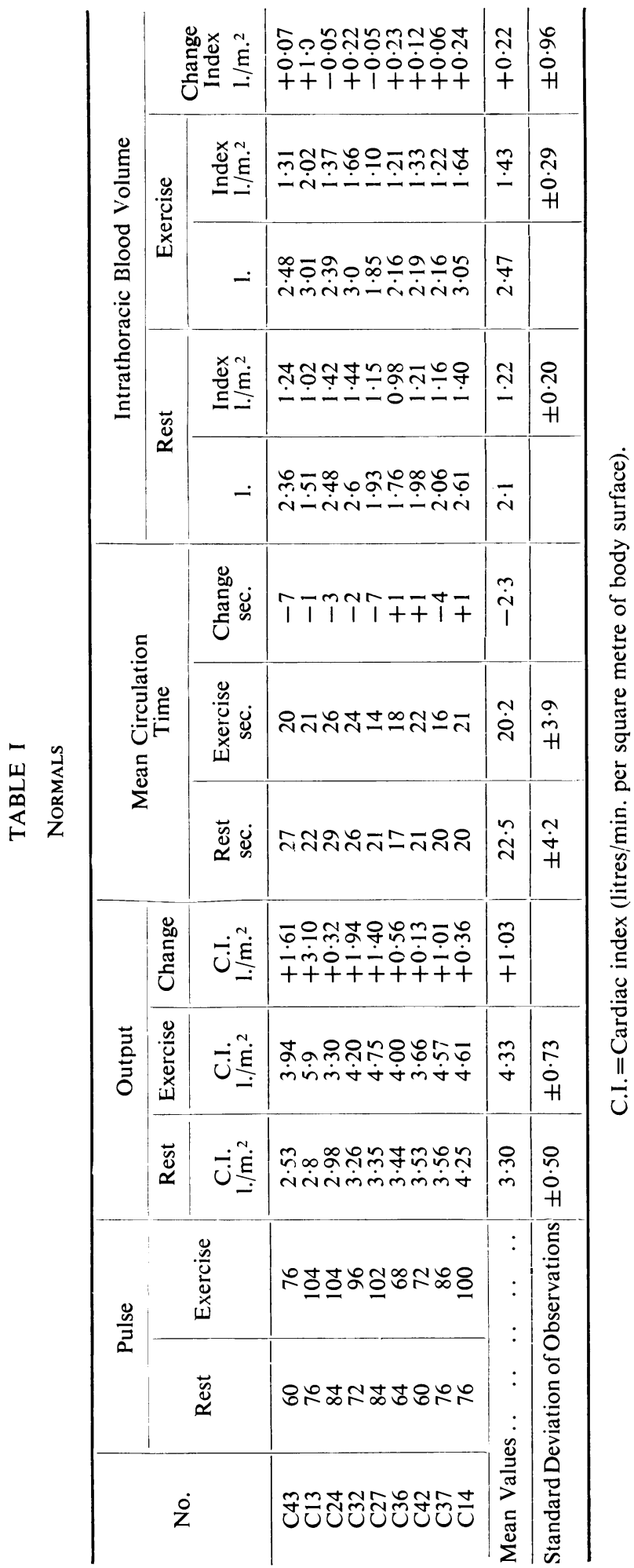


CIRCULATORY CHANGES IN MITRAL STENOSIS

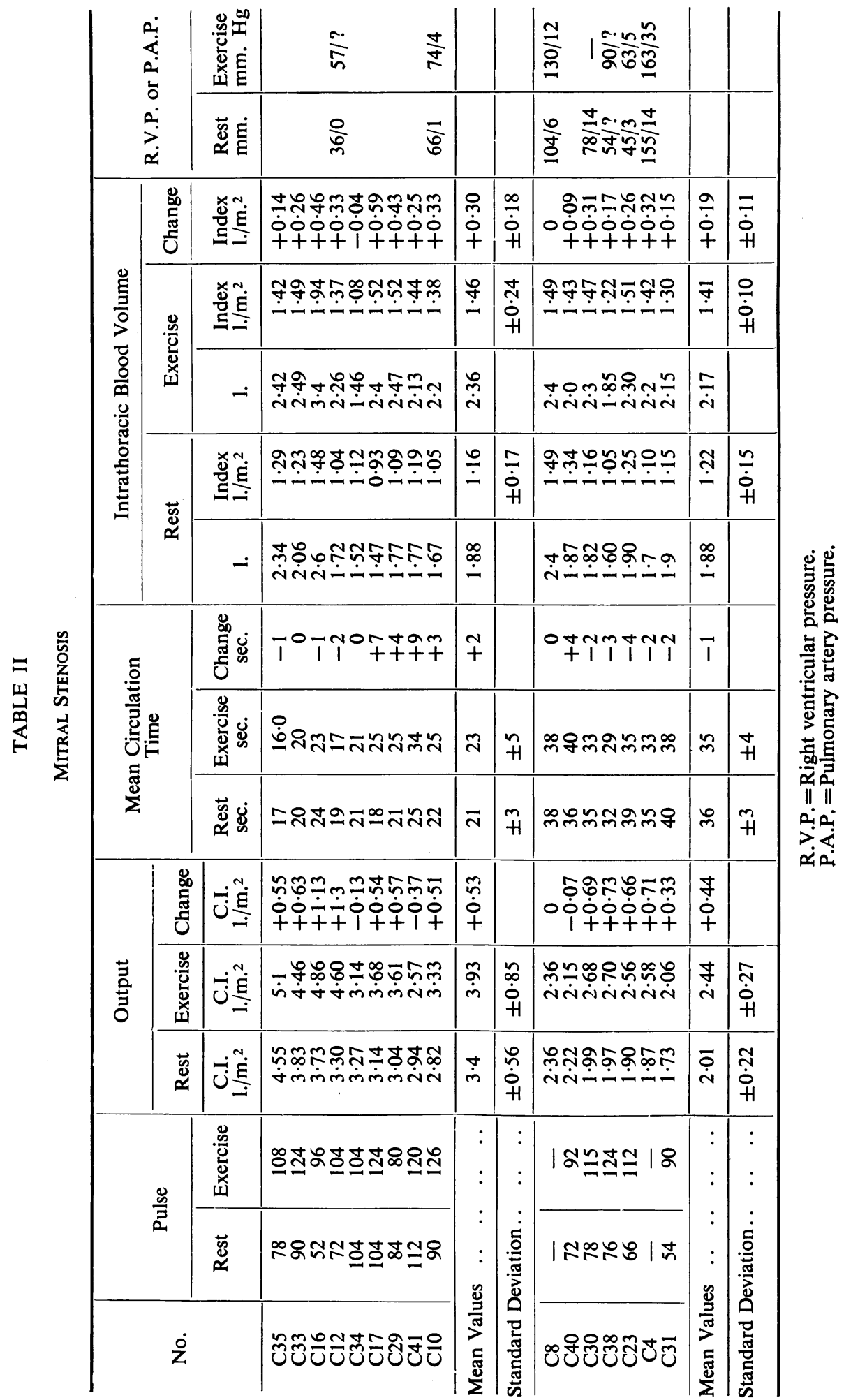




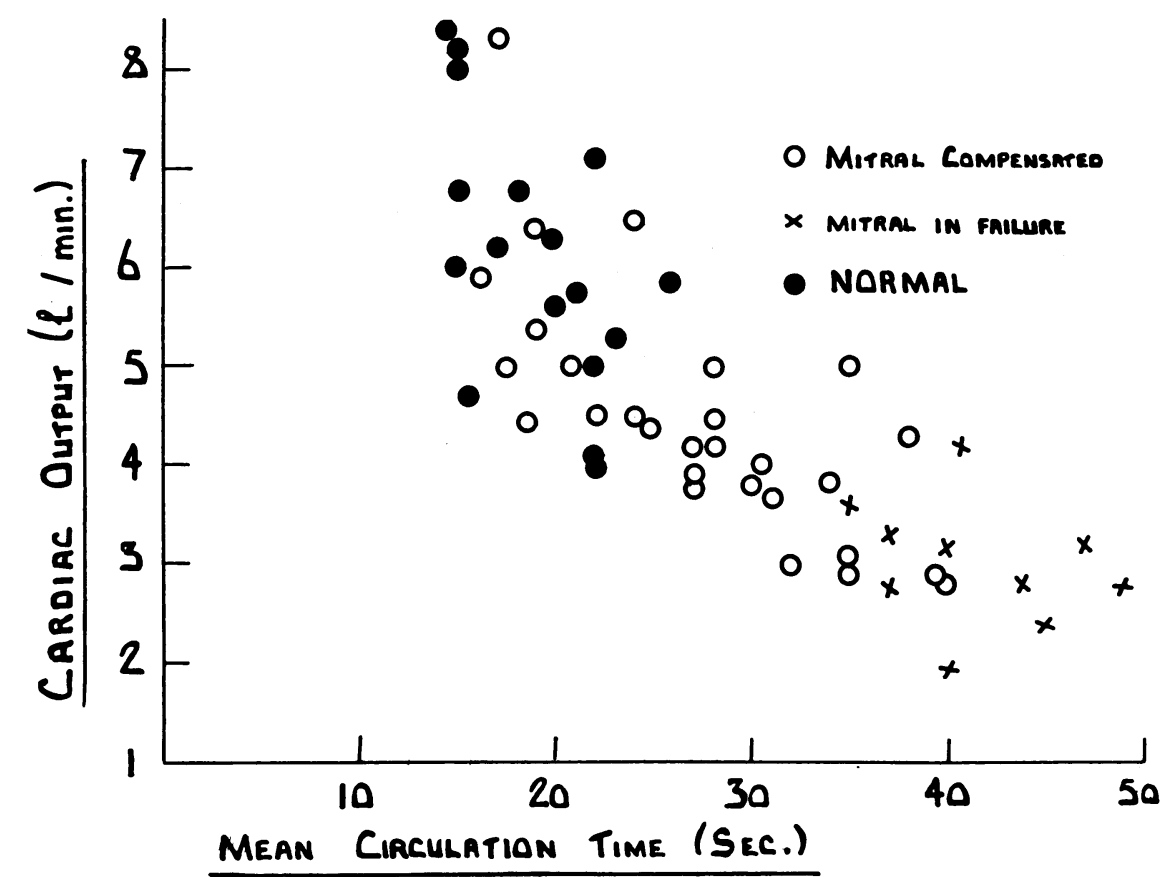

FIG. 2.-Relation between the resting cardiac output and the mean circulation time in normals and in mitral stenosis. From present data and that of Kopelman and Lee (1951).

that they were not strictly basal. Patients with poorer exercise tolerance who had the lower cardiac outputs showed less variation at rest and on exercise as their range of cardiac output was more restricted.

The Intrathoracic Blood Volume. In a previous series (Kopelman and Lee, 1951), no statistically significant difference was found in the intrathoracic blood volume of patients with mitral stenosis and that of normal subjects. The present series confirms this.

The boundaries of the volume of blood referred to as the intrathoracic blood volume cannot be precisely defined, but have been discussed by Hamilton et al. (1932). It consists of the circulating blood in four main compartments, the great veins, the heart, the pulmonary vessels, and the aorta and arteries to the collection point. Cardiac enlargement, as demonstrated by an increase in cardiothoracic ratio was present in 12 of the 16 cases with mitral stenosis and it is therefore probable that these hearts contained more blood than normal. The systemic arterial component is unlikely to have been greatly reduced, especially as many of the patients had normal cardiac outputs. Since in the mitral stenosis patients the intrathoracic blood volume was not greater than normal and the hearts generally contained more blood, there must have been a reduction in the blood volume either in the pulmonary vessels or in the great veins. None of these patients had clinical evidence of congestive failure at the time of the test which might increase the venous component, and it seems unlikely that this volume was less than normal. Thus using this indirect method of deducing the pulmonary blood volume, we reach the rather surprising conclusion that in mitral stenosis at rest the circulating blood volume in the pulmonary vessels is actually reduced. Most of these patients, however, on radioscopy had some enlargement of the main pulmonary arteries, so that if a reduction in pulmonary blood volume does occur, it follows that it must be in the small vessels.

The Effects of Exercise. In the small group of normal subjects studied the cardiac output rose in most cases on exercise. The intrathoracic blood volume increased in some, but in others did not significantly change; in these latter the mean circulation time fell. It has been shown that 


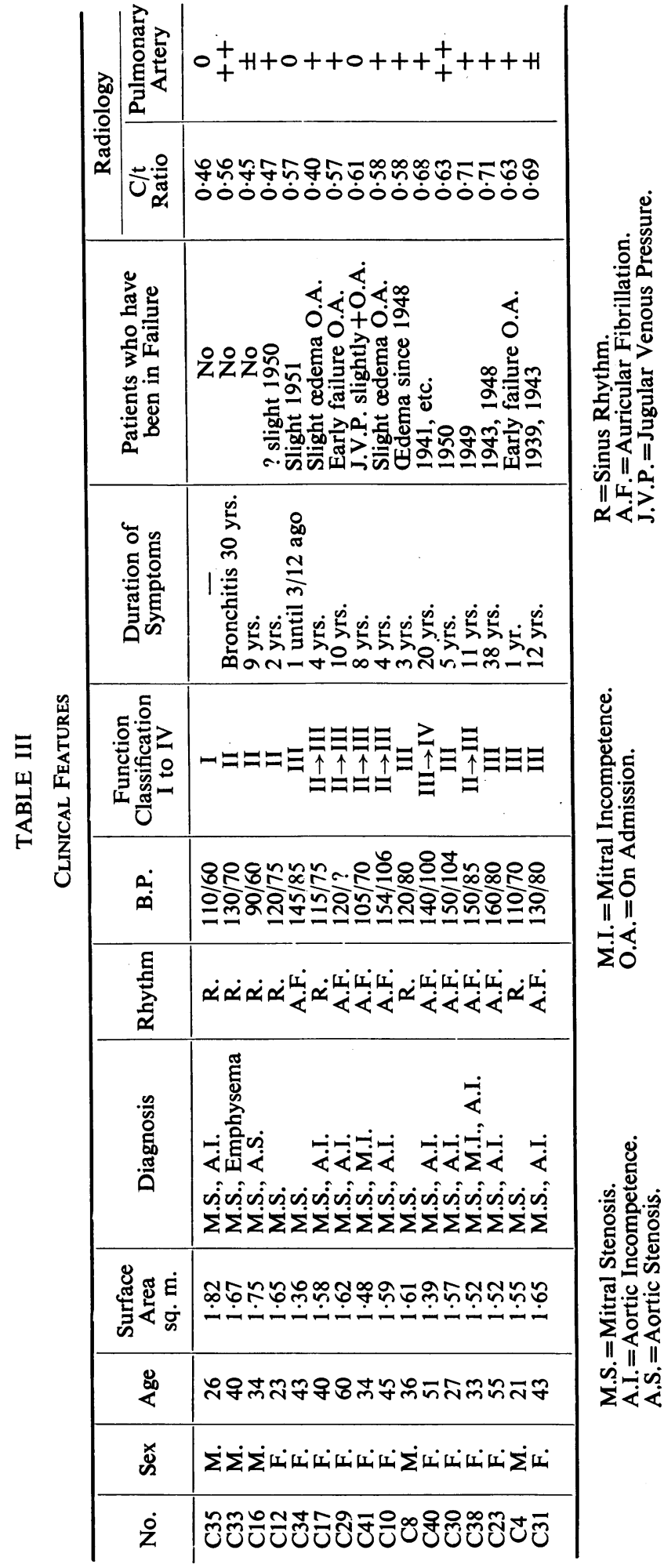


in normal subjects, exercise causes no increase in the pulmonary artery pressure (Riley et al., 1948; Cournand, 1950); or if it does, the rise is only slight (Dexter et al., 1951). Thus in normals despite an increase in output with little or no change in intrathoracic blood volume, there is little change in the pulmonary artery pressure.

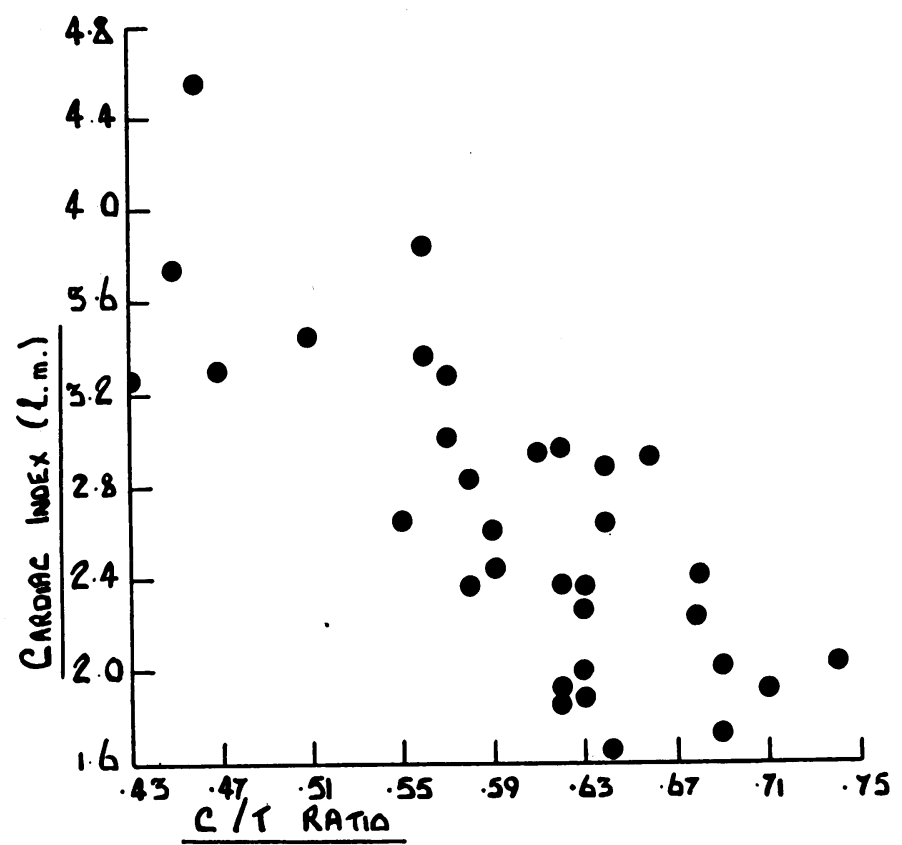

FIG. 3.-Resting cardiac index and heart size as shown by the cardiothoracic ratio in mitral stenosis. $r=-0.78 ; P<0.001$.

The patients with mitral stenosis fall into two main groups-those with normal, and those with low cardiac outputs at rest. Despite differences in the output response, both groups usually show an increase in the intrathoracic blood volume on exercise, more constantly than the normal group. The rise in the low output group is less than in the normal output group, but the difference is not significant. Pulmonary artery or right ventricular pressures were only measured in seven of these cases and these were mainly in those with low outputs. All had a raised pressure at rest which increased further on exercise.

The rise in the intrathoracic blood volume on exercise may occur in any of its four compartments, as previously discussed. In mitral stenosis, especially in the low output group, the venous component might be expected to increase because of the rise in central venous pressure that usually occurs in this type of patient on exercise (Gorlin et al., 1951; Bayliss et al., 1950). It has been observed that patients with mitral stenosis in congestive failure with high central venous pressure show no significant increase in the intrathoracic blood volume (Kopelman and Lee, 1951), and it is unlikely that any slight increase in central venous pressure could cause much increase in this volume. Fig. 4 shows that although there is a close correlation between the central venous pressure and the intrathoracic blood volume in left ventricular failure, this is not so in mitral stenosis and the differences in the pulmonary vessels in these two conditions are probably accounted for. It would thus appear that increase in central venous pressure does not contribute much to the increase in intrathoracic blood volume that occurs on exercise in mitral stenosis. Delay in the dye reaching the heart was minimized by raising the arm above the head and massaging the vein immediately after the injection, and this would compensate for any reduction in venous return from the arm that might occur on leg exercise. It seems unlikely that an increase 


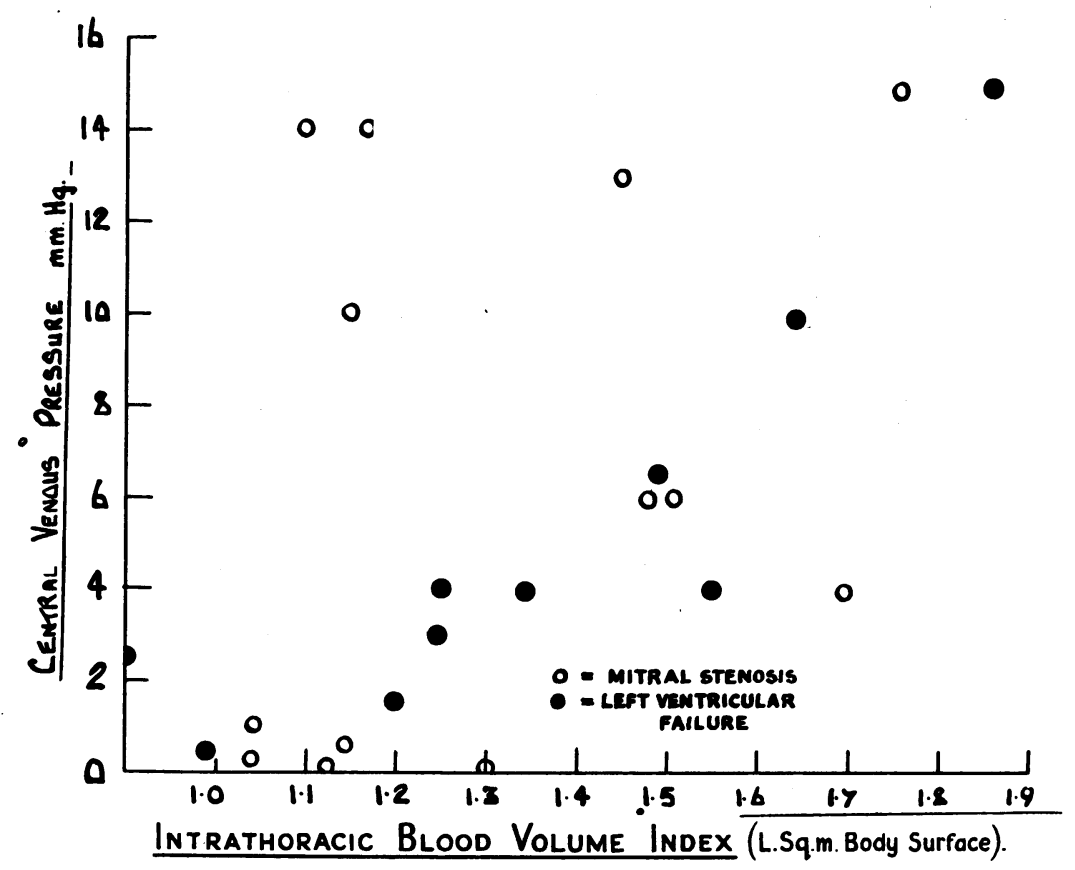

FIG. 4.-Central venous pressure and intrathoracic blood volume index in left ventricular failure and mitral stenosis.

in the aortic and arterial component could account for the rise, and therefore it is probable that the intrathoracic blood volume increase is contained either in the pulmonary vessels or the heart itself. Although no measurable change in the cardiothoracic ratio was observed in any patient on exercise, this does not exclude changes in the size of the left atrium which may enlarge posteriorly. The low output cases had the largest hearts and a small increase in size that hardly shows in the diameter may increase the volume considerably. The normal output cases mainly had smaller hearts and in these an increase of cardiac blood volume should have been more easily detected. The mean circulation time was shortened or unchanged in most cases on exercise, but, in four out of the five normal output cases who showed poor exercise response, this time was greatly prolonged. In the absence of much increase in heart size, this suggests some greater dilatation of the pulmonary vascular bed in these cases.

Hence it appears that the pulmonary blood volume in mitral stenosis may be normal or actually reduced at rest and the reduction when it occurs is probably in the smaller vessels. On exercise, in nearly all cases, there is an increase in the intrathoracic blood volume irrespective of functional capacity, resting cardiac output, or ability to raise the cardiac output. Some of this increase in volume may be in the pulmonary vessels, but the degree to which this occurs may vary in the different groups and the Hamilton dye method is not capable of showing this difference. However, among the patients with a normal cardiac output at rest, there were some with poor exercise responses but with an increase in the thoracic blood volume, accompanied by a prolongation in the mean circulation time; this may be due to a more labile vasculature capable of greater dilatation than the more severe cases.

\section{SummaRY AND CONClusions}

The cardiac output, mean circulation time, and intrathoracic blood volume were measured at rest and during exercise by the Hamilton dye method in nine normal subjects and sixteen patients with mitral stenosis. 
Normal subjects had a mean cardiac index of 3.3 litres at rest and most showed a rise on exercise, the mean being 4.3 litres per square metre. The intrathoracic blood volume was 1.2 litres per square metre at rest; it rose a little in some cases on exercise, but in others showed no significant change and in these the mean circulation time decreased on exercise.

Nine of the mitral stenosis patients had normal resting cardiac outputs with a mean cardiac index of 3.4 litres; the other seven had low cardiac outputs at rest with a mean of 2.2 litres per square metre. The intrathoracic blood volume in these groups was 1.16 litres and 1.22 litres per square metre and was not increased above the volume found in the normal group.

The significance of this is discussed and it is concluded that the pulmonary blood volume in mitral stenosis is normal or reduced when cardiac enlargement is present, and that this reduction takes place in the smaller pulmonary vessels. This is in contrast to the picture in left ventricular failure, where a rise in the pulmonary artery pressure is accompanied by an increased intrathoracic blood volume detectable by the same method.

On exercise the rise in the intrathoracic blood volume in mitral stenosis was approximately the same in both the normal and low output groups. However, other differences in the response to exercise were found in those with normal resting cardiac outputs, so that finally the patients with mitral stenosis could be separated into three groups.

Group 1. These patients had a normal resting cardiac output and mean circulation time and were able to raise their cardiac output to a normal level on mild exercise. The increase in the intrathoracic blood volume on exercise was more consistent than in normals.

These patients were only slightly incapacitated, and their hearts were only slightly, if at all, enlarged. Sinus rhythm was present and none had ever been in congestive failure.

Group 2. These showed only a small rise in cardiac output on exercise, although they had a normal resting output and mean circulation time. The increase in the intrathoracic blood volume on exercise was often accompanied by a prolongation in mean circulation time. This was not found in the other groups.

These patients were in Grade II to III functional capacity. Auricular fibrillation and cardiac enlargement were often present. A recent history of mild congestive failure with rapid recovery was common.

Group 3. A low cardiac output at rest was accompanied by a marked prolongation of the mean circulation time in these patients. On exercise, there was a poor response in cardiac output with a fall in stroke output, although most showed a rise in intrathoracic blood volume with the circulation time decreasing or remaining unchanged.

These patients were all fairly severely incapacitated. Auricular fibrillation was often present as well as gross cardiac enlargement. All had histories of congestive cardiac failure, some of long standing. In five of these patients, the pulmonary artery pressure was found to be greatly raised at rest, with further increase on exercise, although the intrathoracic blood volume was no greater than in the other groups.

The change in the intrathoracic blood volume on exercise does not help in differentiating pulmonary vascular changes of a more permanent nature. However, in this respect, the prolongation of the circulation time on exercise in the second group may indicate a more labile vasculature.

\section{REFERENCES}

Bayliss, R. I. S., Etheridge, M. J., and Hyman, A. L. (1950). Lancet, 2, 889.

Borden, C. W., Ebert, R. V., Wilson, R. H., and Wills, H. S. (1949). J. clin. Invest., $28,1138$.

Cournand, A. (1950). Circulation, 2, 641.

Dexter, L., Whittenberger, J. L., Haynes, F. W., Goodale, W. T., Gorlin, R., and Sawyer, C. G. (1951). J. appl. Physiol., 3, 439.

Gorlin, R., and Gorlin, S. G. (1951). Amer. Heart J., 41, 1.

-, Haynes, F. W., Goodale, W. T., Sawyer, C. G., Dow, J. W., and Dexter, L. (1951a). Amer. Heart J., $41,30$.

—_, Sawyer, C. G., Haynes, F. W., Goodale. W. T., and Dexter, L. (1951b). Amer. Heart J., 41, 192. 
Hamilton, W. F., Moore, J. W., Kinsman, J. M., and Spurling, R. G. (1932). Amer. J. Physiol., 99, 534.

Riley, R. L., Attyah, A. M., Cournand, A., Fowell, D. M., Himmelstein, A., Noble, R. P., Remington, J. W., Richards, D. W., Jr., Wheeler, N. C., and Witham, A. C. (1948). Amer. J. Physiol., 153, 309.

Hickam, J. B., and Cargill, W. H. (1948). J. clin. Invest., 27, 10.

Kopelman, H., and Lee, G. de J. (1951). Clin. Sci., 10, 383.

Lagerlöf, H., Werkö, L., Bucht, H., Holmgren, A. (1949). Scand. J. clin. and Lab. Invest., 1, 114.

Meneely, G. R., and Chesnut, J. L. (1947). Amer. Heart J., 33, 175.

New York Heart Association (1939). Nomenclature and Criteria for diagnosis of Diseases of the Heart. 4th ed. New York: Tuberc. and Health Assoc.

Riley, R. L., Himmelstein, A., Motley, H. L., Werner, H. M., and Cournand, A. (1948). Amer. J. Physiol., $152,372$. Stead, E. A., Jr., Warren, J. V., Merrill, A. J., and Brannon, E. S. (1945). J. clin. Invest., 24, 326.

Stewart, G. N. (1921). Amer. J. Physiol., 58, 20. 